\title{
The Impact of Communication Skills Training on the Adjustment of Opiate Addicts
}

\author{
Zeinab Sirous Jahedi \\ Student of Ph.D, Department of Public Psychology, college of human science \\ Bushehr Branch, Islamic Azad University, Bushehr, Iran
}

Ali Pouladi Reyshahri

Ph.D of Public Psychology, Member of faculty in Payamenoor university of Bushehr Branch

Doi:10.5296/ijhrs.v5i4.8953 URL: http://dx.doi.org/10.5296/ijhrs.v5i4.8953

\begin{abstract}
The present research was aimed to study the impact of communication skills training on the adjustment of opiate addicts. The research was quasi experimental. Statistical population consisted of all addicts in Tehran in 2014-15. Single-stage cluster sampling method was used in the present research so that one of the rehabilitation camps in West of Tehran was selected. Afterwards, 30 addicts were chosen as a sample size using simple random sampling method and were randomly assigned to experimental and control groups. Data collection was carried out based on Bell Adjustment Questionnaire (1961). The reliability was investigated using Cronbach's alpha and the obtained value was equal to 0.84 . Moreover, content validity was employed in order to measure the validity of the test which the questionnaire was approved by the relevant experts and scholars in this regard. Analysis of the obtained data was performed using SPSS software in two parts of descriptive and inferential (Covariance Analysis). Findings indicated that communication skills training leads to an increase in the level of adjustment of addicts in every five dimensions of social adjustment, family adjustment, emotional adjustment, physical adjustment and occupational adjustment.
\end{abstract}

Keywords: Communication skills, social adjustment, emotional adjustment, occupational adjustment 


\section{Introduction}

Addiction is often synonymous with words that have no positive meaning. Addiction is a bitter and tragic situation that affects all aspects of a person's existence so that life is limited to move smoothly in the vicious circle of living and substance abuse. Many competencies, abilities, values, feelings and emotions of the person are what are going to be ruined. According to Mashrouteh (2005), addicts are vulnerable to mental disorders and suicidal tendencies and suicide attempts are of the associated problems. Golparvar and Moradi (2011) indicated in comparison made between psychological characteristics and marital relationships of addicts and non-addicts that addicts and their spouses have more obvious signs of physical disorder, anxiety, insomnia, social dysfunction, depression and aggression. Therefore, substance abuse is associated with vulnerability and physical and mental problems which affect all aspects of one's personal, familial and social life.

Since substance abuse has inhibitory effects on the growth and prosperity of the person, family and society, it is a serious threat and concern. Despite the great efforts of the scientific community, there is not an appropriate solution that can cure the addiction for sure due to the hidden nature of addiction. Addiction is a phenomenon formed by a combination of three factors of biological, psychological and social. Lack of attention to each of these aspects in the process of treatment could lead to no improvement and returning to substance abuse. Undoubtedly, psychological problems of addicts including restoration of self-esteem, responsibility, communication and family problems, and even social issues such as poverty, unemployment, etc. should be paid attention beside drug treatment (Vazirian, 2013).

According to the mentioned complexity of the problem, formation backgrounds, and development and persistence of addiction problem, variety of interventions have been formed in addiction treatment. Application of methods of treatment in terms of individual and group and even society-oriented treatments on one hand, and pharmacotherapy, psychoanalysis and all types of reflective psychotherapy on the other hand have indicate the complexity of this social phenomenon (Azizi, 2010).

Pharmacotherapy is the starting point for most of the addicts. Methadone reduces tendency to drug and even prevents euphoria caused by substance abuse due to cross-tolerance (Farhadi Nasab et al., 2013). Although this method does not lead to complete cessation of substance abuse, it helps to improve social functioning of addicts and reduces physical consequences of addiction, crime, educational, occupational and economic failure, psychological problems such as depression and social and familial disorders associated with addiction (Ekhtiari et al., 2010). This is while many theorists have a theory contrary to it. Accordingly, Tober and Raistrick (2007; cited in Lavasani et al., 2012) believe that even the strongest and most effective opioid antagonists have flaws and limitations and are not enough to treat addiction alone. Moreover, they should be accompanied by psychosocial treatments to achieve the best results.

In this regard, Book et al. (2009) compared social anxiety levels of individuals participated in three groups of N.A., individual therapy and group therapy and indicated that group therapy has the most positive impact on reduction of social anxiety. Ashouri et al. (2012) concluded 
that cognitive-behavioral group therapy has a great impact on improvement of addicts' mental health in addition to reduction of likelihood of relapsing to drug abuse.

On the other hand, some of the researches emphasize the importance of constructive relationships with others in the process of recovery. For instance, Kelly et al. (2011) demonstrated that increase in social relationship leads to reduction of substance abuse and enhancement of prevention activities results in elimination of a wide range of disorders. Cancro (2008) believe that freely expression of feelings and experiences in a safe environment is a significant factor in the recovery process.

Undoubtedly, human relations are necessary to satisfy our basic needs and positive and healthy relationship with others is a key to human growth and perfection. Relationships form a person's behavior in a social context and play an important role in the uniqueness of personality, identity and self-concept at the same time. Shunt and Mcfall (2007, cited in Foad Al-Dini et al., 2012) defined communication skills as multiple processes which enable the person to behave in such a way that others deem him competent. According to the conducted studies, factors such as self-esteem, interpersonal skills, establishment of desirable communication, goal setting, decision making, problem solving and identifying and determining individual values play significant roles in prevention and reduction of variety of behavioral disorders and mental disorders and enhancement of mental health. Honson and Lebenland (2006, cited in Seif \& Islami, 2008) indicated psychological symptoms to couples who had trouble in their relationships and were dissatisfied of their marital life. They also trained the couples in communication skills and conflict resolution. The results declared that such trainings lead to improvement of their relationship, ability to cope with problems and mental health. Accordingly, Ahmadi (2014) conducted a study entitled "effectiveness of communication skills training on learning self-regulation of high school male students" and concluded that communication skills training has positive impact on learning self-regulation. In addition, Ashrafi and Monjazi (2013) demonstrated that communication skills training plays a significant role in reduction of aggressive behaviors of students.

Employment of communication skills training has been also investigated in the field of addiction treatment. Norma (2000) concluded in his research on the effectiveness of communication and social skills training on consequences of drug dependence treatment that such trainings result in improvement of consequences of treatment and elevation of compliance and conformity with society in addicts. Damaris et al. (1991) conducted a study entitled "patient treatment matching for alcoholic men in communication skills versus cognitive-behavioral mood management training" and indicated that social skills training has positive impact on consequences of treatment and participants who were given social skills training experience lower levels of anxiety and compulsion to consume alcohol.

Therefore, according to the complex and multidimensional nature of addiction and taking various therapeutic measures and importance of communication skills in providing indicators such as self-esteem, mental health and social adjustment, the present research aims to answer to the following question. Does communication skills training lead to enhancement of adjustment in opiate addicts? On other words, does communication skills training have 
greater effectiveness on enhancement of adjustment in opiate addicts compared to cognitive and behavioral therapies? In this regard, the research hypotheses are as follows.

$\mathrm{H}_{\mathrm{a}}$ : communication skills training has impact on the level of adjustment of opiate addicts.

$\mathrm{H}_{\mathrm{b} 1}$ : communication skills training has impact on the level of social adjustment of opiate addicts.

$\mathrm{H}_{\mathrm{b} 2}$ : communication skills training has impact on the level of family adjustment of opiate addicts.

$\mathrm{H}_{\mathrm{b} 3}$ : communication skills training has impact on the level of emotional adjustment of opiate addicts.

$\mathrm{H}_{\mathrm{b} 4}$ : communication skills training has impact on the level of physical adjustment of opiate addicts.

$\mathrm{H}_{\mathrm{b} 5}$ : communication skills training has impact on the level of occupational adjustment of opiate addicts.

Eventually, the research conceptual model is presented in Fig. 1.

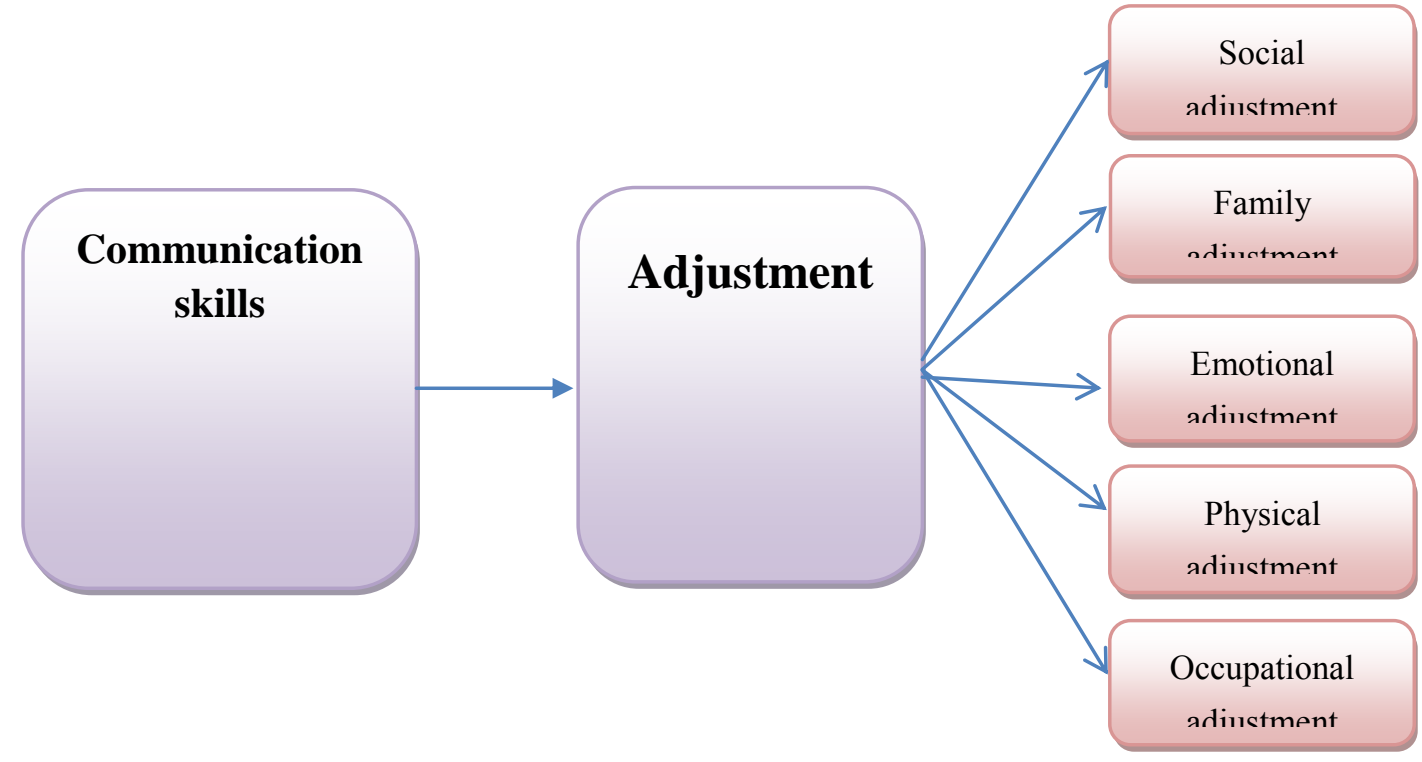

Figure 1. Conceptual model of the research

\section{Methodology}

Since the research was aimed to study the impact of communication skills training on adjustment of opiate addicts, it was a quasi-experimental research with pretest-posttest plan among control group and random assignment in terms of data collection.

Addicts in one of the rehabilitation camps in West of Tehran were trained in communication skills (as independent variable) during seven sessions and the amount of adjustment (as a dependent variable) was studied in pre-test and post-test. Selection criteria were: male gender, aged 20 to 45 years, substance abuse and substance dependence, and third grade middle 
school degree at least. The impact of pre-test on post-test was controlled using variance analysis test.

The population consisted of all addicts in Tehran in 2014-15. Single-stage cluster sampling method was used in the present research so that one of the rehabilitation camps in West of Tehran was selected. Afterwards, 30 addicts were chosen as a sample size using simple random sampling method and were randomly assigned to experimental and control groups.

Data collection was carried out based on the revised version of Bell Adjustment Questionnaire (1961). The questionnaire (adult form) is explained in the following. The adjustment questionnaire was developed by Professor Bell in 1961. He presented two questionnaires in the context of adjustment: one for students and one for adults. The questionnaire used in the present research consisted of 160 questions in five areas of emotional, social, physical, family and occupational (adult form) and educational (student form) in which 32 questions are dedicated to each of the areas.

Self-measurement was chosen as implementation method. Accordingly, participants answer to each of the yes/no questions and the range of scores for each of the scales locates between $0-32$. One's score represents the amount of his/her adjustment. The higher the score, the less the level of adjustment. Therefore, scores in each of the five factors of the questionnaire are interpreted as,

1. Adjustment at home: high scores at this level indicate lack of desirable adjustment with home environment and existence of tension in familial relationship. On the contrary, low scores indicate adjustment at home and satisfaction.

2. Health adjustment: high scores at this level are a sign of undesirable health adjustment and physical complaints. Obviously, low scores are a sign of satisfactory adjustment.

3. Social adjustment: high scores of social adjustment indicate staying away from social contacts and surrounding oneself to others while, while low scores indicate adjustment.

4. Emotional adjustment: individuals with high scores show emotional instability of themselves and have negative emotional symptoms. In addition, individuals with low scores have emotional stability.

5. Occupational adjustment: individuals who get high scores are satisfied with their job and those who get high scores are dissatisfied with their job and face with conflicts at their workplace (Attari et al., 2005).

In order to investigate the validity and reliability of the questionnaire, using retest method, Bell (1962, cited in Fathi Ashtiani, 2009) reported the range of 0.70-0.93 for reliability and 0.74-0.93 for internal consistency coefficient. In the present study, reliability coefficient for the subscales of adjustment at home, health adjustment, social adjustment, emotional adjustment and occupational adjustment were $0.91,0.81,0.88,0.85$ and 0.94 , respectively.

Bell's questionnaire was standardized by Symolen in Iran in 1986 which its reliability was 


\section{Al Macrothink}

International Journal of Human Resource Studies

ISSN 2162-3058 2015, Vol. 5, No. 4

obtained equal to 0.93 using Cronbach's alpha (Kiani, 2010). In addition, Naghshbandi standardized Bell's questionnaire using an 86-person sample which resulted in the same result (Hasanzadeh, 2008). Moreover, Ghasemi (1998, cited in Pour Seied et al., 2010) reported 0.98 for reliability using split half method and 0.99 for correlation coefficient using Spearman-Brown formula.

In the present study, reliability of Bell's questionnaire was found equal to 0.84 using Cronbach's alpha method. Moreover, content validity was employed in order to measure the validity of the test which the questionnaire was approved by the relevant experts and scholars in this regard.

In addition, a summary of the communication skills training sessions is presented in the following table.

Table 1. Sessions of communication skills training

Sessions

First session

Second session

Listening and questioning
Non-verbal and general trainings

\section{Subject}

Developing understanding
Third session

communication

Fourth session
Reward and strengthening

\section{Considerations}

The first session was dedicated to proper communication with others, inspiring confidence and motivating subjects for participating in the program. In addition, there were thorough explanation about general trend of training and activities, and performing tasks and activities.

The second session was dedicated to familiarization with body language, facial emotion recognition, gestures, physical contact, and effective use of body language and non-verbal behavior to express feelings.

The third session was dedicated to verbal aspects of communication such as how to pay appropriate attention to the statements of the other party, how to ask for explanation and clarifying ambiguous points, and summing the heard speech.

The fourth session was dedicated to behavioral consequences of the person on the performance of others such as appropriate strategies to change the behavior of others, strengthening, silence, 
approval and admiration.

Fifth session Explaining and influence

The fifth session was dedicated to the method of clear and perfect exposition of emotion, thoughts, interests and demands, and explaining the consequences of inhibition and suppression of emotions to the person.

The sixth session was dedicated to assertiveness and self-disclosure. In this

Sixth session Self-disclosure session, the subjects learned to have a constructive, perfect and influencing approach to daily events instead of passive or aggressive attitude.

This session was dedicated to topics

Seventh session

Conclusion and training review overview, summing and the subjects' perception of the activities and discussions.

Eventually, analysis of the obtained data was carried out using SPSS software in two parts of descriptive and inferential (Covariance Analysis).

\section{Findings}

In this section, in order to investigate the research hypotheses, the data obtained from Bell's adjustment questionnaire (1961), which was conducted on two groups of experimental and control, were analyzed through SPSS software using variance analysis test at 0.95 confidence level and the results are as follows.

Main hypothesis: communication skills training has impact on the level of adjustment of opiate addicts.

Variance analysis test was employed in order to investigate the main hypothesis of the research which the results are mentioned in table 2. 


\section{Mll Macrothink \\ International Journal of Human Resource Studies \\ ISSN 2162-3058 \\ 2015, Vol. 5, No. 4}

Table 2. Results of covariance analysis testing on adjustment scores (total)

Research variables

Pre-test

Adjustment

(total)

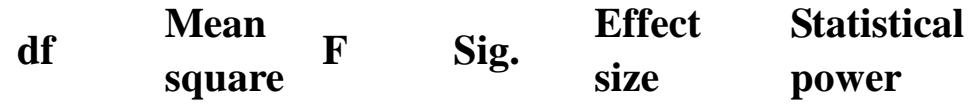

$\begin{array}{llllll}15 & 5482.6 & 21.29 & 0.001 & 0.41 & 0.97\end{array}$

According to the results of ANACO in above table, the main hypothesis is accepted at 0.95 confidence level since the obtained score for F (13.69) is greater than the significance level (0.001). Therefore, it can be concluded that communication skills training leads to improvement of adjustment of opiate addicts. In addition, the statistical power for the variable (0.96) indicates the reliability of the results.

Subsidiary hypotheses: communication skills training has impact on the level of social adjustment, family adjustment, emotional adjustment, physical adjustment and occupational adjustment of opiate addicts.

Variance analysis test was employed in order to investigate the hypotheses of the research which the results are mentioned in table 3 .

Table 3. Results of covariance analysis testing on adjustment scores

\begin{tabular}{|c|c|c|c|c|c|c|c|}
\hline \multicolumn{2}{|c|}{ Research variables } & df & $\begin{array}{l}\text { Mean } \\
\text { square }\end{array}$ & $\mathbf{F}$ & Sig. & $\begin{array}{l}\text { Effect } \\
\text { size }\end{array}$ & $\begin{array}{l}\text { Statistical } \\
\text { power }\end{array}$ \\
\hline \multirow{3}{*}{$\begin{array}{l}\text { Social } \\
\text { adjustment }\end{array}$} & Pre-test & 15 & 524.30 & 39.27 & 0.001 & 0.46 & 0.65 \\
\hline & $\begin{array}{l}\text { Group } \\
\text { membership }\end{array}$ & 15 & 141.64 & 9.93 & 0.001 & 0.68 & 0.85 \\
\hline & Pre-test & 15 & 501.34 & 41.17 & 0.001 & 0.38 & 0.96 \\
\hline \multirow[t]{2}{*}{$\begin{array}{l}\text { Family } \\
\text { adjustment }\end{array}$} & $\begin{array}{l}\text { Group } \\
\text { membership }\end{array}$ & 15 & 144.23 & 11.13 & 0.001 & 0.68 & 0.96 \\
\hline & Pre-test & 15 & 411.61 & 22.14 & 0.001 & 0.46 & 0.97 \\
\hline $\begin{array}{l}\text { Emotional } \\
\text { adjustment }\end{array}$ & $\begin{array}{l}\text { Group } \\
\text { membership }\end{array}$ & 15 & 267.45 & 14.32 & 0.001 & 0.58 & 0.93 \\
\hline Physical & Pre-test & 15 & 210.20 & 11.97 & 0.001 & 0.23 & 0.90 \\
\hline
\end{tabular}


adjustment

$$
\begin{aligned}
& \text { Group } \\
& \text { membership }
\end{aligned}
$$

Pre-test

\section{5}

91.88

15

$$
313.44
$$

15.50

0.001

0.37

0.74

Occupational adjustment
15
145.89
0.001

0.46

0.70

According to the results of ANACO in above table, the subsidiary hypotheses are accepted at 0.95 confidence level since the obtained scores for $\mathrm{F}$ are greater than the significance levels (0.001). Therefore, it can be concluded that communication skills training leads to improvement of social adjustment, family adjustment, emotional adjustment, physical adjustment and occupational adjustment of opiate addicts. In addition, the statistical powers for the variables indicate the reliability of the results.

\section{Conclusion}

The present research was conducted with the aim of studying the impact of communication skills training on the adjustment of opiate addicts in one of the rehabilitation camps in West of Tehran. Addicts and their spouses have more obvious signs of physical disorder, anxiety, insomnia, social dysfunction, depression and aggression. Therefore, substance abuse is associated with vulnerability and physical and mental problems which affect all aspects of one's personal, familial and social life (Golparvar \& Moradi, 2011). Hence so many therapeutic approaches have been adopted in dealing with this illness which resulted in variety of findings. On the other hand, undoubtedly, human relations are necessary to satisfy our basic needs and positive and healthy relationship with others is a key to human growth and perfection. The approach of communication skills has been formulated to develop positive and effective relationship with others and has achieved so many success in reduction of aggressive behaviors, enhancement of self-esteem, marital adjustment and academic attainment.

Results of the present research indicated that communication skills training leads to improvement of adjustment of opiate addicts. It can be expressed in explaining the findings that communication skills training leads to elevation of the level of individual capabilities and one's sense of self-esteem on one hand, and development of communications network and attraction of more social support due to providing the possibility to use the learned capabilities in society and interpersonal relationships on the other hand. Moreover, Kaplan et al. (1984, cited in Karmian, 1999) deemed self-esteem as a major factor in drug abuse and its prevention. In this regard, if the person is frequently exposed to negative evaluation and criticism of others, his honor is declined, and he often humiliate himself and feel incompetent. When a person feels he is rejected by others, he takes many measures such as rebellion against conventional norms and values, avoiding common pattern of imprinting and tendency to deviant peers who admit his behavior to defend himself against isolation and social exclusion. In this regard, according to Kashani et al. (2003), adjusted individuals have good 
self-concept, supporting parents and satisfactory social support systems.

Based on what have been mentioned, the research findings are in line with the results of Kelly et al. (2011), Cancro (2008), Damaris et al. (1999), Ahmadi (2014), Ashrafi and Monjazi (2013) and Attari et al. (2005).

The research findings also demonstrated that communication skills training leads to improvement of family adjustment of opiate addicts. Although it seems that all humans are responsible for their own activities and health, it is somehow more complicated in the issues related to addiction and addicts. In this regard, specialists named it "addict-maker family". This term is used to show the behavioral pattern ruling the family in which there is a blaming atmosphere associated with pain and lack of attention to the wishes and feelings of the person. The family in which solution to even minor and less important issues is found in dispute and conflict instead of dialogue and understanding, there is less empathy and no support and protection at critical and stressful moments, and the person may lead to addiction in case of not having the right skills to cope with these events. Accordingly, Zeinali et al. (2013) concluded in their investigation about drug addiction backgrounds that unhealthy social and familial relationships are of the most important factors of tendency to addiction.

Therefore, the present study's findings are in line with the researches of Kelly et al. (2011), Damaris et al. (1999), Ashrafi and Monjazi (2013), Attari et al. (2005) and Cancro (2008).

Furthermore, the findings indicated that communication skills training leads to improvement of emotional adjustment of opiate addicts. It can be expressed in explaining the finding that making a proper relationship with others, developing human relations network and appropriate expression of emotions play a significant role in emotional draining, happiness and mental health of the person. In this regard, Cancro (2008) found that A.A. and N.A. result in better consequences compared to individual and even medical treatment. According to him, this comes from the safety ruling N.A. meetings and groups, because this safety makes others share their feelings and experiences. He believes that such participations lead to elimination of embarrassment and shame, enhancement of social communication and hope in the person. The hope which is the main cause of addiction according to him.

Based on this, it can be said that the findings are in line with the results of Kelly et al. (2011), Cancro (2008), Damaris et al. (1999), Ahmadi (2014), Ashrafi and Monjazi (2013) and Attari et al. (2005).

Findings declared that communication skills training leads to improvement of physical adjustment of opiate addicts. Substance abuse is in close relationship with variety of disease and physical disorders including lung problems, sexual disabilities, physical stress and emotional lethargy. Undoubtedly, physical pain and muscle tension reaches its peak during detoxification and stopping using drug. It is obvious that body returns to its normal condition after complete cessation of consumption and with the passage of time. However, the person's psychological features and feelings play a significant role in the meantime. On one hand, level of social activities rises and on the other hand, positive feelings such as hope, happiness and satisfaction encompasses the person's mind. 
Obviously, the findings are in line with the results of Ahmadi (2014), Ashrafi and Monjazi (2013), Kelly et al. (2011), Cancro (2008), Norma et al. (2000), Damaris et al. (1999) and Attari et al. (2005).

It can be found from findings that communication skills training leads to improvement of occupational adjustment of opiate addicts. As mentioned before, communication skills training leads to elevation of individuals' capabilities to make constructive relations and develop social relationships. Undoubtedly, individuals who have better skills in their workplace create better work atmosphere, make much better relationships with others and are more serious at work due to the existence of a fresh look at life, positive emotions and hopes for the future and family relationships, and paying special attention to the future and fate. Therefore, these individuals would be able to appropriately handle problems and issues in workplace using problem-solving strategies and dialogue and away from non-constructive and aggressive behavior.

Generally, it can be expressed in explaining the research findings that maladaptive behaviors result from wrong ideas about yourself and the environment. In this view, alcohol and drugs are maladaptive mechanisms which can be reduced by enhancement of problem-solving skills and adaptive skills (Bahari, 2009). Accordingly, Simon et al. (1995, cited in Bahrami Ehsan, 2009) considered low self-esteem, confusion (stress, anxiety and depressed mood), weak coping skills (using denying, avoidance and ignorance defense mechanisms) and weak social interaction skills (being excessively strict and courageous, impetuosity, discourtesy, incompatibility with others and personal valuation system which is based on short-term and personal goals instead of long-term goals based on family, education and religion) in explaining addiction which should be paid special attention in the process of treatment.

According to what have been mentioned, the present findings are in line with the results of Kelly et al. (2011), Norma et al. (2000), Cancro (2008), Damaris et al. (1999), Ahmadi (2014), Ashrafi and Monjazi (2013) and Attari et al. (2005).

Therefore, the following recommendations are proposed according to the research findings.

- Presence in rehabilitation camps and identifying addicts in order to hold communication skills training freely after the period of detoxification.

- To consider a formulated plan in order to train communication skills as training workshops at different levels of education, especially high school, by the ministry of education.

- To hold communication skills training workshops for suffered social groups such as prisoners committed behavioral crimes, adolescents living in Correction and Rehabilitation Center, abandoned children, etc.

- To create relevant courses and develop appropriate educational books in order to make students of psychology and counseling familiar with principles and application of communication skills in treatment.

- To hold communication skills training workshops by experienced psychologists 


\section{Macrothink}

International Journal of Human Resource Studies ISSN 2162-3058 2015, Vol. 5, No. 4

- Mass media should utilize the present results and findings of other similar investigations in order to produce integrated and different programs and campaigns to train communication skills effectively and correctly for all age groups and different sectors of society.

\section{References}

1. Ahmadi, M.S. (2014). Effectiveness of communication skills training on learning self-regulation of high school male students in Zanjan. Journal of Knowledge and Research in Applied Psychology, Vol. 15, Issue 1.

2. Ashouri, A., Mollazadeh, J. and Mohammadi, N.A. (2012). Effectiveness of cognitive-behavioral group therapy in improvement of coping skills and relapse prevention in addicts. Journal of Psychiatry and Clinical Psychology, Y. 14, Issue 3.

3. Attari, Y.A., Shahni Yeylagh, M., Bashlideh, K. and Kouchaki, M. (2005). Study of the impact of social skills group training on individual and social adjustment of delinquent adolescents in the city of Gonbad-e-Qabus, Journal of Psychology and Educational Science, Vol. 3, Issue 25.

4. Azizi, A.R. (2010). Prevention and treatment of addiction, Mashhad: $4^{\text {th }}$ Press.

5. Bahari, F. (2011). Addiction, Consulting and Treatment (A guide to changes in addictive behavior of addicts). Tehran: Danzhe Press.

6. Bahrami Ehsan, H. (2009). Addiction and prevention process, $3^{\text {rd }}$ Edition, SAMT Press.

7. Book, w. Sarah; Thomas, E. Suzanne, Dempsey, P. Jared, Randall, k. Patrick, Randall \& L. Carrie. (2009). Social anxiety impacts willingness to participate in addiction treatment. Addictive Behaviors, Volume 34, Issue 5, May 2009, Pages 474-476

8. Cancro, Lorraine. (2008). Substance Abuse: A Crisis of Hope. The Exceptional Parent, Boston: Sep 2008. Vol. 38, Issue 9; pg. 79, 3 pgs.

9. Damaris J. Rohsenow, Peter M. Monti, Jody A. Binkoff, Michael R. Liepman, and Ted D. Nirenberg. (1991). Patient treatment matching for alcoholic men in communication skills versus cognitive-behavioral mood management training. Addictive Behaviors, Vol. 16, pp. 63-69, 1991.

10. Ekhtiari, H., Behzadi, A., Sadeghi, M., Miriha, H., Norouzi, L., Alavi, A.H. and Jahangiri, B. (2010). A guide to diagnosis and treatment of addiction in Iran, 2nd Edition, Tehran: Arjomand Press.

11. Eshrafi, M. and Monjazi, F. (2013). Effectiveness of communication skills learning on the extent of aggression of high school female students, Journal of Researches in Behavior and Cognitive Sciences, Issue 3.

12. Farhadi Nasab, A. and Mani Kashani, Kh. (2013). Study of the impact of methadone 


\section{Ml Macrothink}

International Journal of Human Resource Studies ISSN 2162-3058 2015, Vol. 5, No. 4

therapy on depression after addiction treatment in Hamadan. Scientific Journal of Ilam Medical Sciences University, Vol. 19, Issue 2.

13. Fathi Ashtiani, A. and Dastani, M. (2009). Psychological-Personality evaluation and mental health tests, Tehran: Be'that Press.

14. Foad Al-Dini, M., Makri, A. and Shafaroudi, N. (2012). The relationship between communication skills and coping performance among addicts in community-focused centers in Tehran. Journal of Thoughts and Behavior, Y. 10, Issue 3.

15. Golparvar, M. and Molavi, H. (2011). Comparison between psychological features and marital relationships of addicts and non-addicts with their wives. Journal of Knowledge and Research in Educational Science, Issue 7.

16. Hasanzadeh, L. (2008). Effectiveness of positive self-talk group training on elevation of social adjustment among third grade high school students in Babolsar, M.A. Thesis, Alame Tabatabaie University, Tehran.

17. Kashani, J.H., Rosenberg, T., Beck, N.C, Reid, J.C. and Battle, E.F. (2003). Characteristics of well-adjusted adolescents. Canadian Journal of Psychiatry; 32: 418-422.

18. Kelly, John F. Stout, Robert L. Magill, Molly. Tonigan and J. Scott. (2011). The role of Alcoholics Anonymous in mobilizing adaptive social network changes: A prospective lagged mediational analysis. Drug and Alcohol Dependence 114 (2011) 119-126.

19. Kiani, S. (2010). Study of the relationship between emotional intelligence, resiliency and social adjustment in order to explain mental health model among students in Shahed University in 2009-10, M.A. Thesis in Measurement and Evaluation, Alame Tabatabaie University of Tehran.

20. Lavasani, F., Atef Vahid, M.K., Asgharnezhad Farid, A.A. and Farzad, V.A. (2012). Study of effectiveness of supportive-representative psychodynamic therapy on improvement of consequences of substance abuse treatment. Journal of Contemporary Psychology, Vol. 4. Issue 2.

21. Mashrouteh, M. (2005). Study of risk of suicide among relatives of drug addicts attended to Shahid Beheshti hospital in order to treat addiction, Ph.D. dissertation in Kerman University of Medical Sciences.

22. Mo'arefvand, M. (2013). Study of personal, familial and social relationships on relapse prevention in rehabilitated addicts, Ph.D. dissertation in University of Social Welfare and Rehabilitation.

23. Norma G. Bartholomew, M.A., Matthew L. Hiller, Ph.D., Kevin Knight, Ph.D., Diane C. Nucatola, M.S., D and Dwayne Simpson. (2000). Effectiveness of communication and relationship skills training for men in substance abuse treatment. Journal of Substance Abuse Treatment 18 (2000) 217-225. 
24. Pour Seied, S.R., Habib Elahi, S. and Faramarzi, S. (2010). Effectiveness of life skills training on the level of adjustment among blind and visually impaired students, Journal of Education Strategies, Vol. 3, Issue 1.

25. Seif, S. and Islami, M. (2008). The role of communication beliefs in performance of family and marital adjustment. Journal of New Thoughts on Education, Issue 14.

26. Vazirian, M.A. and Mostashari, G. (2013). A practical guide to substance abuse treatment. Ministry of Health and Medical Education, Department of Health.

27. Zeinali, A., Vahdat, R. and Isavi, M. (2013). Predisposing groundwork for addiction of rehabilitated addicts, Iranian Journal of Psychiatry and Clinical Psychology, Y. 14, Issue 1. 